Ophthalmologica

\title{
Intravascular Papillary Endothelial Hyperplasia - A Rare Finding in the Orbital Region
}

\author{
Stephan Schulze ${ }^{a}$ Steffen Hoerle ${ }^{a}$ Gudrun Koop ${ }^{c}$ Peter J. Barth ${ }^{b}$ \\ Monika Huegens-Penzel ${ }^{d} \quad$ Ilse Strempel ${ }^{a}$ \\ ${ }^{a}$ Department of Ophthalmology and ${ }^{b}$ Institute of Pathology, University Hospital Giessen and Marburg GmbH, \\ Marburg; Departments of ${ }^{\mathrm{C} O p h t h a l m o l o g y}$ and ${ }^{\mathrm{d}}$ Neuroradiology, University Hospital Giessen and Marburg GmbH, \\ Giessen, Germany
}

\section{Key Words}

Intravascular papillary endothelial hyperplasia •

Orbital tumor · Masson's tumor • Pseudoangiosarcoma

\begin{abstract}
Intravascular papillary endothelial hyperplasia is a benign lesion of vascular origin. It is caused by excessive proliferation of endothelial cells in vascular malformations or normal blood vessels. We report the case of a 58-year-old woman sent to our clinic for surgery of an orbital fat prolapse at her right eye. The clinical examination showed a displacable swelling with a slightly livid aspect approximately $2 \mathrm{~cm}$ in diameter under the upper orbital rim. After MRI, a biopsy was carried out leading to the histological diagnosis of intravascular papillary endothelial hyperplasia. The complete excision of the remaining tumor was performed 8 weeks later. We discuss this clinical entity and the management of such lesions in the orbital region. Copyright $\odot 2008$ S. Karger AG, Basel
\end{abstract}

\section{Introduction}

Unexplained swellings in the orbital region pose a diagnostic dilemma for clinicians. One of the rarely found entities is intravascular papillary endothelial hyperplasia
(IPEH). IPEH is a benign tumor that mostly occurs as an isolated mass in medium-sized veins without association to systemic diseases. It is considered to be a reactive hyperplasia of endothelial cells developing in response to intravascular thrombosis and thrombus organization [1]. Most of the reported cases in the head and neck region affect the skin and the subcutaneous tissue [2]. The median age of patients with IPEH is reported to be 45 years [3].

The lesions tend to recur if incompletely resected. IPEH mostly occurs in the head, neck and extremities and is rarely found in the orbital region or in the eyelids. We report a case of IPEH in the upper eyelid.

\section{Case Report}

A 58-year-old woman was presented for surgical removal of an orbital fat pad. She had been suffering from a slight ptosis and a painless nodular lesion in the right upper eyelid for about 12 months (fig. 1,2).

Examination of the lid revealed a soft, displacable, bluish swelling under the orbital rim bulging during Valsalva maneuver. Ocular motility was not affected by the tumor and the patient did not suffer from diplopia at any time. The intraocular clinical findings were unremarkable, the uncorrected visual acuity was 0.63 in both eyes, with $+0.5 \mathrm{sph}=0.8$.

Magnetic resonance imaging disclosed a $2.5 \times 1.5 \times 1.5 \mathrm{~cm}$ mass in the right medial upper eyelid filling up subcutaneous space completely (fig. 3 and 4). Axial and sagittal $\mathrm{T}_{1^{-}}$and $\mathrm{T}_{2^{-}}$

\section{KARGER}

Fax +41613061234

E-Mail karger@karger.ch

www.karger.com
(C) 2008 S. Karger AG, Basel

0030-3755/08/2223-0213\$24.50/0

Accessible online at:

www.karger.com/oph
Stephan Schulze, MD

Department of Ophthalmology, University Hospital Giessen and Marburg Philipps University Marburg, Robert-Koch-Strasse 4

DE-35033 Marburg (Germany)

Tel. +496421 28 62600, Fax +4964212865678, E-Mail schulzes@med.uni-marburg.de 
Fig. 1. Nodular lesion in the right upper eyelid bulging during Valsalva maneuver. Fig. 2. Transpalpebral access showing the vascular tumor.

Fig. 3. Magnetic resonance imaging demonstrating the palpebral nodular tumor.

Fig. 4. MRI showing small coagulations or calcifications within the tumor.
1

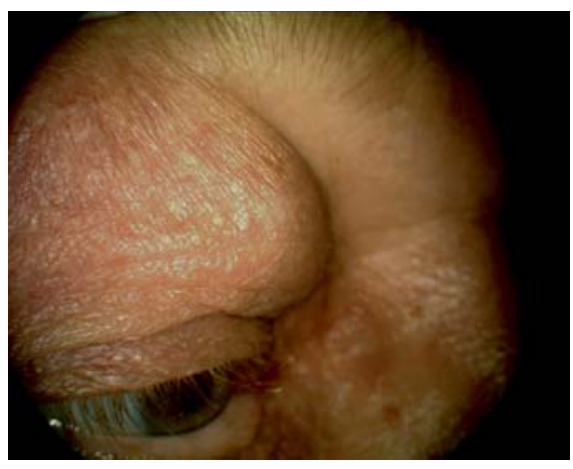

2

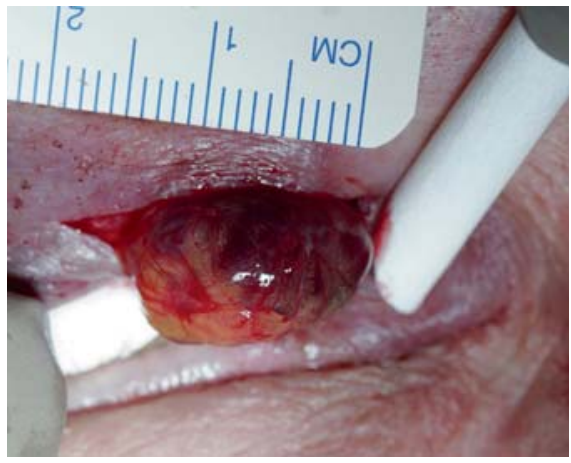

3

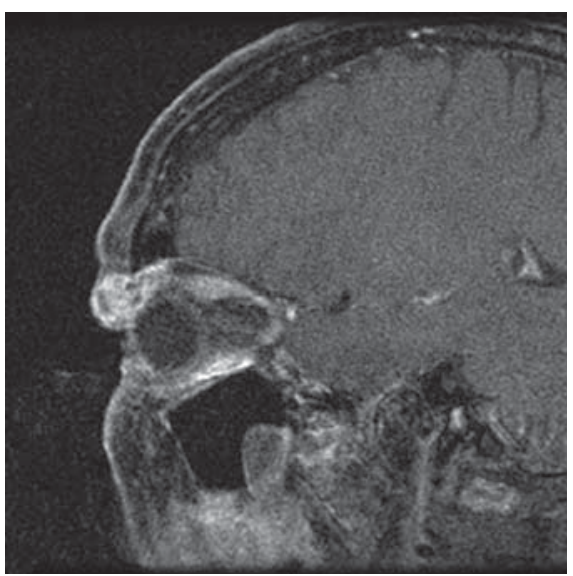

4

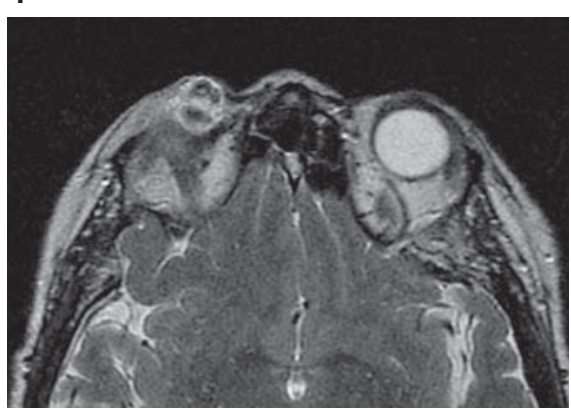

weighted images showed inhomogeneous signals representing small coagulations or calcifications within the tumor. The structure was located above the superior rectus muscle and the bulbus extending approximately up to the bulbus equator without infiltration of the bulbus or orbital structures and without intraconal extension.

The biopsy of this lesion, which was carried out through a transpalpebral access, revealed adilated vein with a large, partially organized thrombus (fig. 5) surrounded by closely packed myofibroblasts and anastomosing vascular channels harboring plump papillary projections lined by plump endothelial cells. The hyperplastic endothelium showed immunohistochemical positivity for CD31 and displayed no atypia. The diagnosis of an intravascular angiomatosis (IPEH) was made.

Eight weeks later, a complete excision of the IPEH was performed without complications. The patient has been followed-up for 12 weeks without any recurrence.

\section{Discussion}

Masson [4] was the first to describe an atypical vascular proliferation, which he named 'vegetant intravascular hemangioendothelioma'. The entity is now called 'intra-

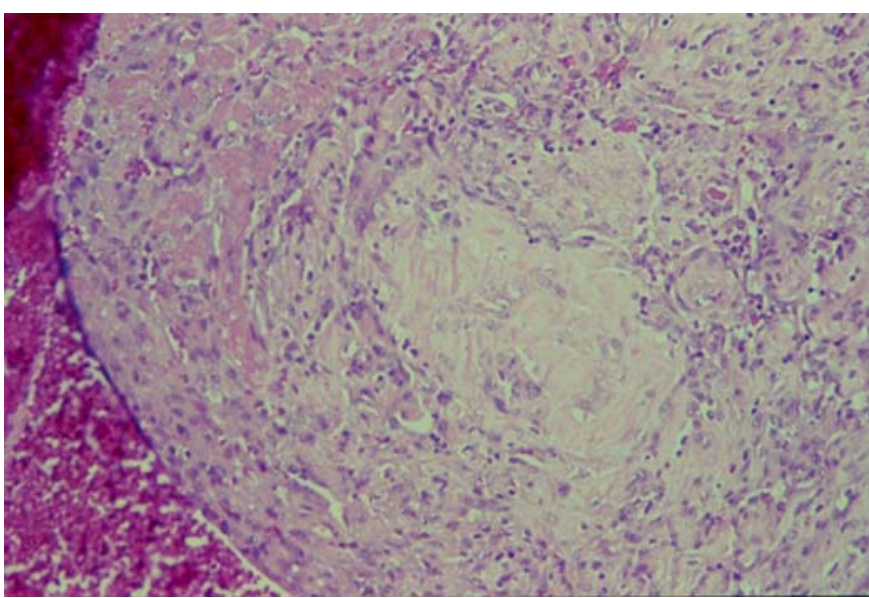

Fig. 5. Microphotograph displaying a dilated vein filled by a thrombus in varying stages of organization being typical for IPEH. Myofibroblasts, vessels with enveloped papillary fronds and hyperplastic endothelium. 
vascular papillary endothelial hyperplasia' and has been described in various body sites. The lesion is predominantly situated subcutaneously in the head, neck and extremities, and it is rarely found in the orbital or lid region [5]. Clinically, IPEH appears as a small, firm, superficial mass leaving the overlying skin with a slight red to blue discoloration [6]. IPEH represents approximately $2 \%$ of benign and malignant vascular tumors of subcutaneous tissues [7].

IPEH can be found in different vascular proliferations. It predominantly occurs in medium-sized veins but may also arise from pre-existing benign vascular tumors such as pyogenic granuloma, hemangioma and lymphangioma [8].

The diagnosis is based on microscopic examination. The endothelial cell proliferation is histopathologically characterized by confinement to the intravascular space, absence of anaplasia or multiple mitosis, lack of true fibrous papillary fronds and the presence of papillae consisting of fibrohyalinized tissue covered by pleomorphic endothelium [9]. Since it also shows features like plump endothelial cells, papillary configuration, thrombus formation and irregular blood-filled spaces, it may be histologically mistaken for capillary angiosarcoma.

Masson proposed the lesion to be a primarily endothelial proliferation with secondary thrombus formation [4]. Recent authors consider IPEH to be a reactive hyperplastic process of endothelial cells that develops in response to intravascular thrombosis with subsequent organization of the thrombus [1].

IPEH is known to act aggressively when incompletely resected [1]; still, conservative surgical excision is the treatment of choice. When resected completely, recurrence is extremely rare. In cases where complete surgical removal is impossible, adjuvant radiotherapy or chemotherapy leads to stabilization and short-term regression of the lesion. Gamma Knife radiosurgery seems to be effective in smaller lesions not amenable to complete resection [10].

\section{References}

1 Requena L, Sangueza OP: Cutaneous vascular proliferation. II. Hyperplasias and benign neoplasms. J Am Acad Dermatol 1997;37: 887-922.

-2 Pantanowitz L, Muc R, Spanger M, Sonnendecker $\mathrm{H}, \mathrm{McIntosh}$ WA: Intravascular papillary endothelial hyperplasia (Masson's tumor) manifesting as a lateral neck mass. Ear Nose Throat J 2000;79:806-812.

- 3 Font RL, Wheeler TM, Boniuk M: Intravascular papillary endothelial hyperplasia of the orbit and ocular adnexa. A report of five cases. Arch Ophthalmol 1983;101:17311736.
4 Masson P: Hémangioendothéliome végétant intravasculaire. Bull Soc Anat 1923;23:517523.

5 Werner MS, Hornblass A, Reifler DM, Dresner SC, Harrison W: Intravascular papillary endothelial hyperplasia: collection of four cases and a review of the literature. Ophthal Plast Reconstr Surg 1997;13:48-56.

-6 Moon WS, Chung GH, Hong KH: Intravascular papillary endothelial hyperplasia in a vascular lesion of the paranasal sinus. Arch Pathol Lab Med 2000;124:1224-1227.

7 Amerigo J, Berry CL: Intravascular papillary endothelial hyperplasia in the skin and subcutaneous tissue. Virchows Arch A Pathol Anat Histol 1980;387: 81-90.
Kuo TT, Gomez LG: Papillary endothelial proliferation in cystic lymphangioma. Arch Pathol Lab Med 1979;103:306-308.

9 Kuo TT, Sayers P, Rosai J: Masson's 'vegetant intra-vascular hemangioendothelioma': a lesion often mistaken for angiosarcoma. Cancer 1976;38:1227-1236.

10 Ohshima T, Ogura K, Nakayashiki N, Tachibana E: Intravascular papillary endothelial hyperplasia at the superior orbital fissure: report of a case successfully treated with Gamma Knife radiosurgery. Surg Neurol 2005;64:266-269. 